\title{
An experimental study of the influence of pressure pulsations in the water turbine flow path on vibration parameters of the hydraulic unit
}

\author{
Dmitry Dekterev ${ }^{1,2^{*}}$, Dmitry Platonov ${ }^{1,2}$, Andrey Minakov ${ }^{1,2}$, Alexandra Maslennikova $^{1}$ and \\ Artem Abramov ${ }^{1}$ \\ ${ }^{1}$ Siberian Federal University, 79 Svobodny Ave., 660041 Krasnoyarsk, Russia \\ ${ }^{2}$ Institute of Thermophysics, SB RAS, 1 Lavrentyev Ave., 630090, Novosibirsk, Russia
}

\begin{abstract}
The paper presents an experimental study of the relationship between the vibration of the water turbine unit and the pressure pulsations in the flow path. It is shown that the air injection into the flow path leads to a decrease in the hydraulic turbine vibration associated with the formation of the precessing vortex core.
\end{abstract}

\section{Introduction}

Hydropower is a significant part of the overall energy system. The reliability of the hydropower equipment operation is largely determined by its vibrational parameters. Vibrational signal is the sum of signals from all elements of the mechanism and hydromechanical processes that occur during the operation of a water turbine. It is generally believed that the most significant contribution of hydrodynamic processes is in the so-called transient modes of operation of the hydraulic unit (partial or high load). In such regimes a stable vortex structure with a pronounced precession frequency formed downstream the water turbine runner. The precessing vortex core (PVC) leads to generation of high amplitude low-frequency pressure pulsations [1,2], which are the most dangerous in the case of resonance with the elements of the hydraulic turbine. In this case arising vibrations leads to a faster wear of the equipment and destruction of some unit elements. This work was carried out to determine the effect of pressure pulsations in the water turbine flow path on the vibration of its construction.

\section{Experimental techniques}

An experimental study was carried out at the research set-up with a model of a water turbine unit at a scale of 1/14.7. The main units of the set-up: the water storage tank, two regulated pumps, pressure tank, model of the hydraulic unit (spiral case, stator columns,

* Corresponding author: dekterev_da@mail.ru 
guide vanes, runner $(\mathrm{D}=0.3 \mathrm{~m})$, transparent conical diffuser and draft tube), drain tank and set of flowmeters.

The opening of the guide vanes regulates by manual and electrical drives and is divided into 15 steps. The optimum operating mode by integral characteristics of the hydraulic unit and the pressure pulsation parameters in the flow path is the $9 / 15$ opening. In this paper the modes with constant water head $3.5 \mathrm{~m}$ for the guide vanes opening $1 / 15-8 / 15$ was studied. The water turbine works at "free runner" mode. The frequency of the runner was determined using the optical tachometer $(340-510 \mathrm{rpm}$ depending on the guide vanes opening) and the frequency of the PVC was determined with the help of piezoelectric pressure sensors installed in wall of conical diffuser. A stable vortex core was visually observed at operating conditions corresponding to the openings 3/15-5/15 (Fig. 1a), at the opening of 6/15 a large unstable spiral vortex was observed (Fig. 1b), in the mode of 7/15 a thin unstable vortex with the reconnection effect was observed (Fig. 1c), and at the 8/15 mode no vortex structures were observed.
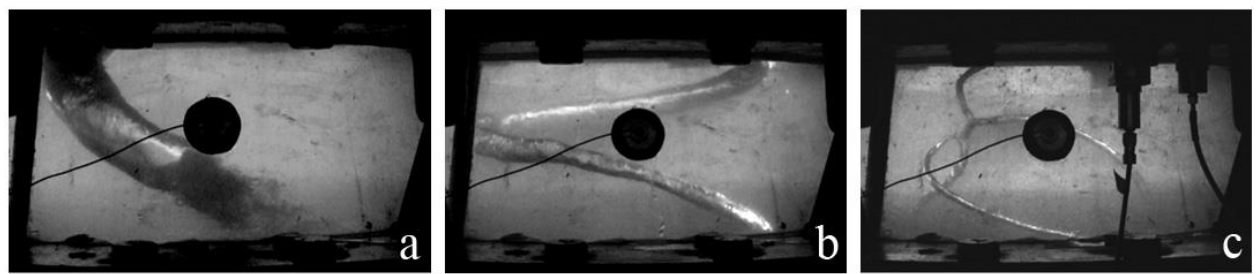

Fig. 1. Varieties of vortices downstream the runner

\section{Experimental results}

Investigation of the vibration parameters of the hydraulic turbine unit was carried out using a piezoelectric vibration acceleration sensor VD06A which was installed on conical diffuser flange. The signal was transmitted to a $\mathrm{PC}$ via $\mathrm{ADC}$ and recorded in $\mathrm{mV}$. Spectra with evident frequency of the precession of the vortex core and the rotation frequency of the runner are obtained using a fast Fourier transform. Figure 2 shows the vibration spectrum for the mode with the opening of the guide vanes $4 / 15$.

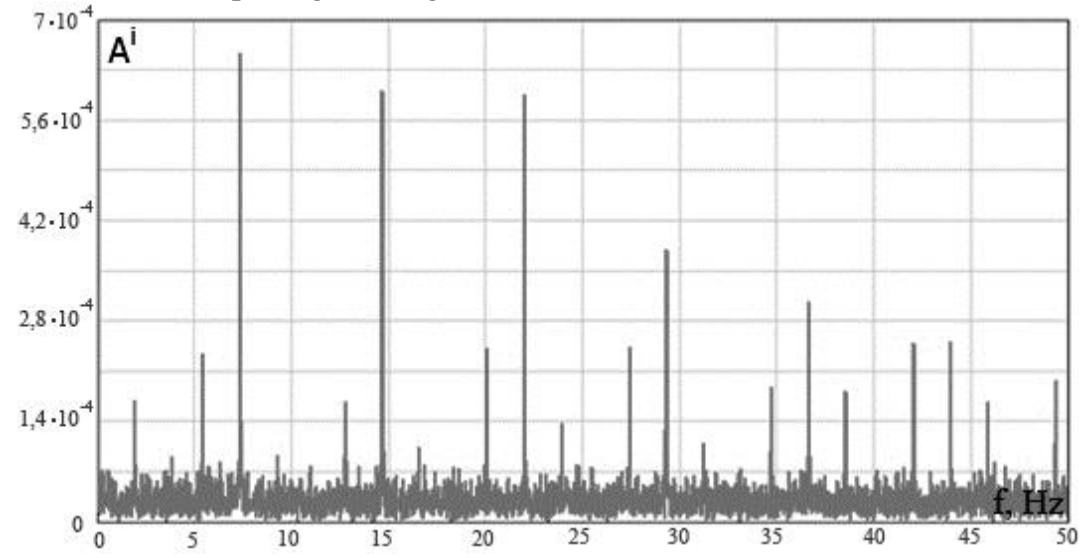

Fig. 2. Vibration spectrum

The first peak at a frequency of $1.9 \mathrm{~Hz}$ corresponds to the PVC frequency, the peak at a frequency of $7.3 \mathrm{~Hz}$ corresponds to the rotation frequency of the runner $(438 \mathrm{rpm})$. Harmonics of the runner rotation frequency are also visible; in addition, noticeable peaks are equidistant from the rotation frequency (including harmonics) to a positive and negative 
value equal to the PVC frequency are observed. This means that pressure pulsations make a serious contribution to the appearance of low-frequency vibrations. A similar dependence is observed for the $1 / 15-5 / 15$ openings. When the opening is $6 / 15$ and above, only the double rotational frequency of the runner is observed.

The plot of the dependence of the vibration signal amplitude (peak to peak) on the opening of the guide vanes shows that the maximum of vibrations is observed in the case of openings $2 / 15-3 / 15$, however, approaching the optimal operating modes of the turbine the signal intensity is significantly reduced.

Recently, various works have been conducted to study methods of decreasing of pressure pulsations in a flow with a precessing vortex core, including injection of air into the turbine flow path $[3,4]$. In this work, air is also injected to the set-up, and its effect on the vibration level of the hydraulic unit is evaluated. Figure 3 shows the comparison of peak-to-peak vibration signal level with and without air injection.

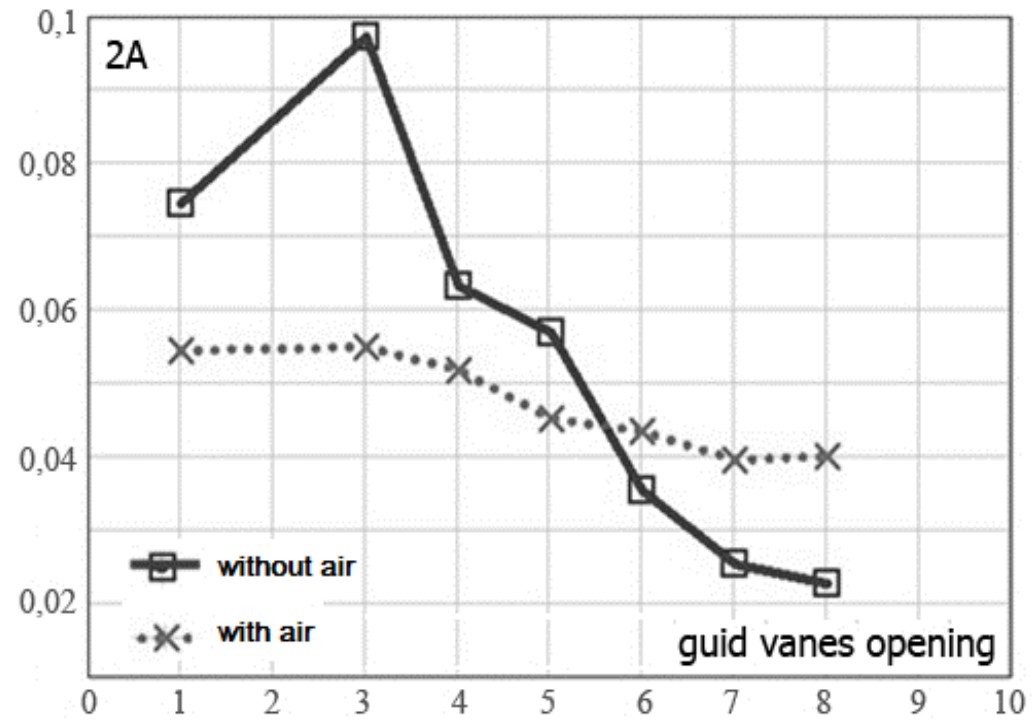

Fig. 3. Effect of air injection to vibration signal level

In this study, the airflow rate was constant and amounted to $6.3 \mathrm{~m}^{3} / \mathrm{h}$; it corresponds to $3.6 \%$ of the water flow rate when opening of guide vanes is $1 / 15$ and $1.4 \%$ when opening is $8 / 15$. It may be noted that the air injection reduces the level of vibration signal at the nonoptimal operating modes of the hydraulic unit up to $45 \%$ for $3 / 15$ opening. At the same time air injection leads to increase of signal in the cases close to the optimal mode, however, the increased signal does not exceed the signal level at non-optimal modes. Hence, one can draw conclusions about the advisability of using air to reduce vibrations only in non-optimal operating modes of hydraulic units.

\section{Conclusions}

It is showed that the pressure pulsations generated by the precessing vortex core make an appreciable contribution to the emergence of low-frequency vibration of the hydraulic unit.

It has been established that the injection of air into the flow path of a hydraulic unit in order to reduce the amplitude of vibration is appropriate only in cases of operating of water turbine in non-optimal modes. The question of determining the minimum sufficient volume of injected air remains rather interesting. 
The work was performed at partial support of the projects funded by the Russian Foundation for Basic Research and Krasnoyarsk Regional Fund for Support of Scientific and Scientific-Technical Activities (16-48-243076).

\section{References}

1. A.K. Gupta, D.G. Lilley, N. Syred, Swirl flows (Abacus Press, 1984)

2. S. Alekseenko, P. Kuibin, V. Okulov, Theory of concentrated vortices. An introduction, (Springer, 2007)

3. G. Semenov, A. Smirnova, A. Dekterev, A. Minakov, A. Sentyabov, Proceedings of the Hydro 2012, Bilbao, Spain, 9 (2012)

4. S.V. Alekseenko, P.A. Kuibin, V.L. Okulov, S.I. Shtork, Vortex precession in a gasliquid flow, Heat Transfer Research, 41465 (2010) 